\title{
PENERAPAN SANKSI PELANGGARAN LALU LINTAS \\ MENURUT PASAL 77 UNDANG-UNDANG NOMOR \\ 22 TAHUN 2009 TENTANG LALU LINTAS \\ (STUDI KASUS DI POLRES SINTANG)
}

\author{
Gadion \\ Fakultas Hukum Universitas Kapuas Sintang \\ Jalan Oevang Oeray 92 Sintang \\ Email : gadion_unka@gmail.com
}

\section{Abstrac}

The Police as a law enforcement institution has the authority in applying Sanction of Traffic Violation through Traffic Unit which is assigned in every process of violation by motor vehicle driver. other than that Traffic Unit also need to carry out appeal and give information to the public that every motor vehicle must complete the conditions that must be implemented and obeyed by every motorist one of them carry the vehicle letters and equip the vehicle with the provisions of Traffic can be worn Law Number 22 Year 2009 regarding Traffic especially Article 77 paragraph 1.

Keywords : Expectations, afance, Traffic

\begin{abstract}
Abstrak
Kepolisian sebagai sebagai institusi penegakan hukum memiliki kewenangan dalam penerapan Sanksi Pelanggaran Lalu Lintas melalui Satuan Lalu Lintas yang bertugas dalam setiap proses pelanggaran oleh
\end{abstract}

pengemudi kendaraan bermotor. selain itu Satuan Lalu Lintas juga perlu melaksanakan himbauan dan meberikan informasi kepada masyarakat bahwa setiap berkendaraan bermotor haruslah melengkapi syarat-syarat yang wajib untuk dilaksanakan dan dipatuhi oleh setiap pengendara bermotor salah satunya membawa surat-surat kendaraan dan melengkapi kendaraan dengan ketentuan Pelanggran lalu lintas dapat dikenakan Undang-undang Nomor 22 Tahun 2009 tentang lalu Lintas khusunya Pasal 77 ayat 1. Kata Kunci : Penarapan, Pelanggaran, Lalu Lintas

\section{Latar Belakang}

Konsep hukum yang didefinisikan oleh sebuah laporan dari kontrak dan Perjanjian (yang hasil dari negosiasi antara sama dalam hal hukum), kedua dalam hubungan dengan sumber-sumber hukum lainnya: tradisi (dan kebiasaan), kasus hukum, undang-undang dasar, dan peraturan-peraturan dan tindakan 
tertulis lainnya dari eksekutif, sementara undang-undang adalah karya legislatif, sering diwujudkan dalam parlemen yang mewakili rakyat.

Menurut Undang-undang Nomor 22 Tahun 2009 tentang Lalu Lintas dan angkutan jalan pasal 2 memberikan pengertian adalah kesatuan system yang terdiri atas lalu lintas, angkutan jalan, jaringan lalu lintas dan angkutan jalan, kendaraan, pengemudi, pengguna jalan, serta pengelolaannya. ${ }^{1}$

Dilihat dari isi pasal 2 undang-undang Nomor 22 Tahun 2009 menyatakan bahwa ada satu kesatuan dalam system berlalu lintas serta keterkaian antara penggguna jalan maupun dengan jaringan dan apa bila perbuatan tersebut dilangga maka akan dikenakan sankisi, sanksi merupakan keharusan bagi setiap orang untuk diterima sebagaimana pelanggaran atau akibat dar perbuatan yang dilakukan, agar terlaksananya ketertiban dan keselarasn dalam berkendara.

Kota Sintang merupakan penduduk yang pada saat sekarang ini perkembangan penduduknya dalam kemajuan yang sangat pesat, sehingga laju perekonomian di Kota Sintang pada saat sekarang ini sangat meningkat denagn banyaknya permintaan baik sandang maupun pangan, oleh sebab

1 Undang-Undang Lalu Lintas Angkutan Jalan, Fokusindo mandiri Bandung 2013 hal 2 itu kebutuhan dari setiap orang bermacammacam salah satunya adalah mempunyai kendaraan guna melancarkan atau menunjang kegiatan-kegtiatan baik perekonomian maupun kegiatan sehari hari. Untuk memiliki salah satu kenadaraan, maka setiap warga masyarakat yang menggunakan dan menjalankan kendaraan haruslah melengkapi diri dengan ketentuan-ketentuan yang berlaku dan mengikuti tatacara berlalu lintas yang sesuai dengan peraturan perundang-undangan yang berlaku.

Sudikno Martokusumo menyatakan ada 3 (tiga) hal yang harus diperhatikan dalam penegakan hukum yaitu :

1. Kepastian Hukum (rechtssicherheit)

2. Kemanfaatan (zweckmassigkeit)

3. Keadilan (gerechtigkeit) $)^{2}$

Selain dalam hal penegakan hukum yang dilakukan oleh kepolisian dalam menjalankan dan melaksanakan tugas, POLRI juga melaksanakan himbauan dan meberikan informasi kepada masyarakat bahwa setiap berkendaraan bermotor haruslah melengkapi syarat-syarat yang wajib untuk dilaksanakan dan dipatuhi oleh setiap pengendara bermotor salah satunya membawa surat-surat kendaraan dan melengkapi kendaraan dengan ketentuan misalnya kaca spion dan lampu kendaraan.

2 Martokusmo, sukdino, Bab-bab Tentang Penemuan Hukum, yokyakarta, PT. Citra Aditya Bhakti hal : 1 


\section{Pembahasan}

\section{A. Gambaran Umum Lokasi Penelitian}

Kepolisian Resort Sintang (Polres) merupakan Institusi Polri yang mempunyai tugas pokok Polri sebagai pemelihara keamanan, ketertiban masyarakat serta penegakan hukum untuk memberi perlindungan, pengayoman, dan pelayanan kepada masyarakat di wilayah hukum Polres Sintang. Wilayah hukum Polres Sintang terletak di Kabupaten Sintang, sebuah Kabupaten di Provinsi Kalimantan Barat di wilayah Timur. Dalam melaksanakan tugas Polrtes Sintang selalu bekerja sama dengan instansi dan masyarakat yang diharapkan akan dapat membantu keberhasilan Polriyang maksimal. Keberhasilan Polri khususnya Polres Sintang akan membawa dampak positif terhadap masyarakat, sehingga dapat mempengaruhi kinerja Polres sintang untuk baik kedepannya.

Polres sebagai alat penegak hukum bertugas untuk memelihara keamanan dan ketertiban masyarakat yang berada diwilayah hukumnya. Gangguan kamtibnas sering kali terjadi terutama dalam berlalu lintas, seperti pelanggaran dan kejahatan di jalan raya. Sehingga sebagai sebuah institusi diperlukannya struktue organisasi untuk memperlancar tugas dan wewenang dari masing-masing bagian dalam Polres Sintang, sehingga tidak terjadi tumpang tindih ataupun kekacauan dalam menjalankan tugas pada institusi tersebut.

Satuan lalu Lintas (Sat lantas) dalam struktur organisasi Polres Sintang, sesuai Peraturan Kepala Kepolisian Negara Republik Indonesia nomor 23 Tahun 2010 tentang Susunan Organisasi dan tata kerja pada tingkat kepolisian Resort dan Kepolisian Sektor bertugas melaksanakanj :

1. Pengaturan, penjagaan, pengawalan, dan patroli (turjawali lalu lintas.

2. Pendidikan Masyarakat Lalu Lintas (Dikmas lantas)

3. Pelayanan Registrasi dan Identifikasi Kendaraan Bermotor dan Pengemudi

4. Penyidikan Kecelakaan lalu Lintas dan Penegakan Hukum di bidang lalu lintas.

Dalam melaksanakan tugas tersebut, Sat lantas Polres sintang Menyelenggarakan fungsi :

1. Pembinaan Lalu Lintas Kepolisian

2. Pembinaan partisipasi masyarakat melalui kerja sama lintas sektoral, dikmas lantas dan pengkajian masalah dibidang lalu lintas

3. Pelaksanaan operasi kepolisian dibidang lalu lintas dalam rangka penegakan hukum dan keamanan, keselamatan, ketertiban, kelancaran lalu lintas.

4. Pelayanan administarsi registrasi dan identifikasi kendaraan bermotor serta pengemudi

5. Pelaksanaan patroli jalan raya dan penindakan pelanggaran serta penanganan kecelakaan lalu lintas dalam rangka npenegakan hukum, serta menjamin kamseltibcar lantas di 
jalan raya.

6. Pengamanan dan penyelamatan masyarakat pengguna jalan

7. Perawatan dan pemeliharaan peralatan dan kendaraan.

Satlantas Polres Sintang dipimpin oleh Kepala Satuan lalu Lintas (kasat lantas) yang bgertanggung jawab kepada Polres Sintang dan dalam pelaksanaan tugas sehari-hari dibaawah kendali Wakapolres. Kasat lantas memiliki Tugas yaitu:

1. Menyelenggarakan atau membiana fungsi lalu lintas yang meliputi :

a. Pengaturan

b. Pengaalan dan patroli

c. Pendidikan masyarakat bidang lantas

d. Rekayasa lantas

e. Registrasi dan identifikasi ranmor atau pengemudi,

f. Penyidikan laka lantas

g. Penegakan hukum bidang lantas guna terciptanya kamseltibcar lantas

2. Menyelenggarakanb pembinaan partisipasi masyarakat melalui kerja sama lintas sektoral, dikmas lantas dan pengkajian maslah dibidang lalu liontas.

3. Melaksanakan operasi kepolisian dibidang lalu lintas dalam rangka penegakan hukum dan keamanan, keselamatan ketertiban, kelancaran lalu lintas.

4. Menyelenggarakan pelayanan administrasi registrasi dan identifikasi ranmor serta pengemudi

5. Melaksanakan patroli jalan raya dan penindakan pelanggaran serta penanganan laka lantas dalam rangka penegakan hukum serta menjamin kamseltibcar lantas dijalan raya.

6. Menyelenggarakan pengamanan dan penyelamatan masyarakat pengguna jalan raya.

\section{B. Penegakan Hukum oleh Satuan lalu Lintas Polres Sintang terhadap Pelanggar yang Tidak mempunyai Surat Izin Mengemudi}

Satuan Polisi Lalu Lintas Polres Sintang telah melakukan penegakan dan sanksi bagi pengemudi yang tidak melengkapi diri dengan Surat Izin Mengemudi (SIM), mengingat kelengkapan bagi setiap orang atau masyarakat dalam kelayakan untuk menggunakan atau mengendarai kendaraan yang sesuai dengan aturan dan peraturan yang berlaku bagi setiap orang dijalan raya.

Berdasarkan data yang diperoleh penulis dari Satuan lalu Liontas Polres Sintang, sejumlah pelangagaran lalu lintas yang ditinjau dari Golongan Surat Izin Mengemudi pada Bulan Mei tahun 2015 adalah sebagai berikut :

Tabel 4.2.1 Daftar Pelanggaran Lalu Lintas

Dari Golongan Sim Mei 2011

\begin{tabular}{|c|c|c|c|c|c|c|c|c|c|}
\hline \multirow[b]{2}{*}{ NO } & \multirow[b]{2}{*}{$\begin{array}{r}\text { Jml } \\
\text { GAR }\end{array}$} & \multicolumn{8}{|c|}{ Golongan SIM Pelanggar } \\
\hline & & A & $\begin{array}{c}\text { A } \\
\text { UMUM }\end{array}$ & B. 1 & $\begin{array}{c}\text { B.1 } \\
\text { UMUM }\end{array}$ & B.II & C & $\begin{array}{c}\text { A } \\
\text { KHUSUS }\end{array}$ & $\begin{array}{c}\text { TANPA } \\
\text { SIM/ } \\
\text { KR }\end{array}$ \\
\hline 1 & 279 & & & & & & 279 & & \\
\hline 2 & 188 & 1 & & & & & 187 & & \\
\hline 3 & 220 & 1 & & 2 & & & 217 & & \\
\hline 4 & 200 & 2 & & 3 & & & 195 & & \\
\hline 5 & 126 & & & & & & 126 & & \\
\hline JML & 1013 & 4 & & 5 & & & 1004 & & \\
\hline
\end{tabular}

Sumber Kepolisian Resor Sintang Tahun 2015 
Berdasarkan tabel diatas menunjukan bahwa pengemudi kendaraan berdasarkan golongan SIM (surat izin mengemudi) menunjukan bahwa pengendara yang tidak melengkapi SIM adalah kendaraan yang pengemudinya dengan jenis golongan SIM C, dengan jumlah sebanyak 1004 pengendara yang tidak melengkapi diri dengan SIM Golongan C. Sedangkan pengendara yang tidak melengkapi diri dengan jenis golongan A sebanyak 4 pengendara, dan pengendara yang tidak melengkapi diri dengan golongan B1 sebanyak 5 pengendara, jadi total pengendara yang tidak melengkapi dri dengan Surat izin mengtemudi (SIM) sebanyak 1004 pengendara.

Dari hasil observasi penulis dan tanya jawab terhadap responden dikantor Kepolisian Resor Sintang menunjukan bahwa pelanggaran lalu lintas bukan hanya diakibatkan pengendara tidak melengkapi diri dengan surat izin mengemudi (SIM) akan tetapi jenis pelanggaran lain juga mengikuti seperti Helm, Kelengkapan kendaraan, suratsurat, boncengan lebih dari satu orang, maka rambu, melawan arus, berikut ini tabel data pelanggaran lalu lintas Roda dua pada bulan Mei Tahun 2015.
Tabel 4.2.2 Data Pelanggaran lalu Lintas roda dua Bulan Mei Tahun 2015.

\begin{tabular}{|c|c|c|c|c|c|c|c|c|}
\hline \multirow{2}{*}{ NO } & \multirow{2}{*}{$\begin{array}{r}\text { Jml } \\
\text { GAR }\end{array}$} & Helm & $\begin{array}{r}\text { Klp } \\
\text { kendaran }\end{array}$ & $\begin{array}{r}\text { Surat- } \\
\text { Surat }\end{array}$ & $\begin{array}{r}\text { Boncengan } \\
\text { lbh 1 org }\end{array}$ & $\begin{array}{c}\text { Marka } \\
\text { Rambu }\end{array}$ & $\begin{array}{c}\text { Melawan } \\
\text { Arus }\end{array}$ & Ket \\
\hline 1 & 279 & 10 & 134 & 233 & & 2 & & \\
\hline 2 & 187 & 15 & 94 & 72 & & 4 & 2 & \\
\hline 3 & 217 & 2 & 122 & 86 & & 4 & 3 & \\
\hline 4 & 195 & 4 & 85 & 106 & & & & \\
\hline 5 & 126 & 4 & 78 & 42 & & 2 & & \\
\hline JML & 1004 & 35 & 513 & 439 & & 12 & 5 & \\
\hline
\end{tabular}

Sumber Kepolisian Resor Sintang Tahun2015

Dari tabel diatas menunjukan bahwa pelanggaran lalu lintas pada bulan Mei Tahun 2015 sebanyak 1004 jumlah pelanggaran, sedangkan untuk pelanggaran yang tidak memiliki surat-surat sebanyak 513 pelanggaran termasuklah pengendara yang tidak melengkapi surat izin mengemudi (SIM).

\section{Sanksi Bagi Pengendara Yang Tidak melengkapi Surat Izin Mengemudi (SIM).}

Setiap orang yang mengendarai kendaraan bermotor roda dua sampai dengan kendaraan yang lebih dari roda empat, maka pengendara tgersebut haruslah melengkapi diri dengan surat izin mengemudi, yang dikeluarkan oleh Kepolisian bagian satuan Lalu Lintas dengan memenuhi beberapa persyaratan yang harus dilengkapi. Apabila pengendarta yang didapati tidak melengkapi surat izin mengemudi maka pengendara tersebut dapatlah dikenakan dengan pasal 77 
ayat 1 Undang-Undang Nomor 22 Tahun 2009 Tentang Lalu Lintas dan Angkutan Jalan " Setiap orang yang mengemudikan kendaraan bermotor dijalan wajib memiliki surat izin mengemudi sesuai dengan jenis kendaraan bermotor yang dikemudikannya" dan menurut pasal 281 junto "setiap orang yang mengemudikan kendaraan bermotor dijalan raya yang tidak memiliki surat izin mengemudi sebagaimana yang dim,aksud dalam pasal 77 ayat 1 dipidana dengan pidana kurungan paling lama 4 bulan atau denda paling banyak 1.000.000,- (satu juta rupiah).

Berikut data dan jenis pelanggaran lalu lintas roda empat bulan Mei Tahun 20015.

Tabel 4.3.1 Jenis Pelanggaran lalu Lintas Roda Empat bulan Mei Tahun 2015

\begin{tabular}{|c|c|c|c|c|c|c|c|c|}
\hline \multirow[b]{2}{*}{ NO } & \multirow{2}{*}{$\begin{array}{r}\text { Jml } \\
\text { GAR }\end{array}$} & \multicolumn{7}{|c|}{ Jenis Pelanggaran Yang Dilakukan } \\
\hline & & Kecepata & Muatan & $\begin{array}{c}\text { Kelengkapan } \\
\text { kendaraan }\end{array}$ & $\begin{array}{l}\text { Surat- } \\
\text { surat }\end{array}$ & sabuk & $\begin{array}{l}\text { Marka } \\
\text { rambu }\end{array}$ & Ket \\
\hline 1 & & & & & & & & \\
\hline 2 & 1 & & & & 1 & & & \\
\hline 3 & 3 & & & & 3 & & & \\
\hline 4 & 5 & & & & 5 & & & \\
\hline 5 & & & & & & & & \\
\hline JML & 9 & & & & 9 & & & \\
\hline
\end{tabular}

Sumber Kepolisian Resor Sintang Tahun 2015

Dari tabel diatas menunjukan bahwa kendaraa roda empat yang pengendaranya tidak melengkapi surat-surat sebanyak 9 pengendara, surat-surat disini berarti bahwa pengendara tersebut tidak mempunyai surat STNK maupun SIM, yang seharusnya setiap pengendara untuk dapat membawa dan menggunakan surat tersebut sebagai bukti bahwa layak untuk mengendarai kendaraan roda empat.

\section{Faktor Pennghambat Kepolisian dalam melaksanakan Penerapan pasal 77 Undang-Undang Nomor 22 Tahun 2009 Tentang Lalu Lintas dan angkutan Jalan}

Dalam menjalankan sebuah aturan hukum yang sering kali terdapat ketidak tahuan masyarakat tentang suatu aturan hukum merupak suatu kendala didalam mewujudkan hukum di lingkung masyarakat luas, untuk itu menurut Soerjono Soekamto menyampaikan bahwa "Tegaknya hukum ditandi dengan adanya beberapa factor yang saling berkaitan erat yaitu hukum dan aturannya sendiri”. Menurut Friedman dalam penegakan hukum pidana ddipengaruhi oleh 3 (tiga) aspek penting yaitu :

1. Legal structure (struktur hukum, dapat diartikan sebagai institusi yang menjalankan penegakan hukum dengan segala proses yang berlangsung didalamnya.institusi ini dalam system yang terdiri atas kepolisian, kejaksaan, pengadilan dan lembaga permasyarakatan yang menjamin berjalannya proses peradilan pidana.

2. Legal substance (subtansi hukum) adalah aturan, norma, dan pola prilaku nyata manusia yang berada didalamm system tersebut.subtansi hukum tidak hanya terpusat pada hukum yang tertulis saja (law in the book),tetapi juga mencakup hukum yangn hidup dimasyarakat(the living law).

3. Legal culture (budaya hukum),sebagai sikap masyarakat terhadap hukum 
dan system hukum itu sendiri. Sikapmasyarakat ini mencakup kepercayaan, nilai dan ide--ide serta harapan mereka tentang hukum dan system hukum. Hal ini karena pada hakekatnya penegakan hukum merupakan proses penyesuaian antara nilai-nilai,kaidah-kaidah dan pola prilakunyata, yang bertujuan untuk mencapai kedamaian. Oleh karena itu tugas utama penegakan hukum adalah mencapai keadilan.

Soerjono Soekanto membuat perincian factor-faktor yang mempengaruhi penegakan hukum sebagai berikut :

1. Faktor hukumnya sendiri, misalnya undang-undang

2. Faktor penegakan hukum yakni pihakpihak yang membentuk maupun yang menerapkan hukum.

3. Faktor sarana atau fasilitas yang mendukum penegakan hukum.

4. Faktor masyarakat, yakni lingkungan dimana hukum tersebut berlaku atau diterapkan.

5. Faktor kebudayaan, yakni hasil karya, cipta dan rasanya yang didasarkan pada karsa manusia didalam pergaulan hidup.

Dilihat kelima factor diatas menunjukan bahwa saling keterkaitan, yang mana penegakan hukum harus dijalan kan sesuai dengan yang diharapkan semua lapisan masyarakat, walaupun masih adanya penerapan hukum yang belum dijalankan sebagaimana mestinya, dikarenakan adanya faktor penegakan hukum baik dari penegak hukum itu sendiri maupun yang menerapkan hukum itu sendiri.
Terjadinya hambatan dalam penegakan hukum juga dilihat dari masyarakat iru sendiri dimana masyarakat sering kali tidak mengindahkan atau melalaikan dari kewajiban untuk mempunyai surat izin mengemudi karena ketidak tahuan ataupun sengaja dalam mempunyai sim (surat izin mengemudi) tersebut.

\section{Simpulan}

Berdasarkan pada pembahasan tersebut dapat disimpulkan bahwa menurut pasal 77 Undang-Undang Nomor 22 Tahun 2009 menyatakan bahwa, setiap orang yang mengemudikan kendaraan bermotor diwajibkan untuk memiliki surat izin mengemudi sesuai dengan jenis kendaraan bernotor yang dikemudikan. Kemudian bagi pengemudi kendaraan yang tidak memiliki surat izin mengemudi maka akan dikenakan denda sebesar 1.000.000,- (satu juta rupiah), atau pidana kurungan paling lama 4 bulan. Faktor penghambat yaitu bahwa adanya kesadaran masyarakat agar memiliki surat izin mengemudi sesuai peraturan yang belaku. Saran penelitian yaitu diharapkan kepolisian dapat memberikan kemudahan dalam pengurusan dan membuat surat izin mengemudi. Memberikan penyuluhan kepada setiap masyrakat dalam mengendarai kendaraan haruslah mempunyai surat izin 
mengemudi, supaya peaturan-lalu lintas dapat

diikuti dan dijalankan dengan baik dan benar

oleh seluruh lapisan masyarakat.

\section{DAFTAR PUSTAKA}

Anang, Priyanto, 2007 Hukum Acara Pidana Indonesia, Yokyakarta, Fise Uny.

Bambang Waluyo, 1991, Penelitian Hukum Dalam Praktek, Jakarta, sinar grafika. Bambang Sugono, 2005, Metode penelitan Hukum, P.T raja Grafindo, Persada, Jakarta

Hadari Nawawi,2007, Metode Penelitian Bidang Sosial, Gajah Mada University Press, Yokyakarta.

Kansil.C.S.T, Pengantar ilmu Hukum dan Tata Hukum Indonesia, Jakarta, balai Pustaka

Marto, Kusumo Sudikno, Bab-Bab Tentang Penemuan Hukum, yokyakarta. PT.Citra Aditya Bhakti.

Muhammad Mulayadi, 2008, Politik Hukum Pidana, Medan, Universitas Sumatra Utara.

Raharjo,Satjipto, 2009 Penegakan Hukum Suatu Tinjauan Sosiologis, Genta Publishing.

Ronny Hanitijo Soemitro,1983, Metode Penelitian Hukum, Jakarta, Ghalia Indonesia.

Soemitro, Ronny Hanitijo, 1990, Metodologi Penelitian Hukum dan jurimetri, Jakarta Ghalia Indonesia.

Soemitro, Ronny Hanitijo, 1990, Metodologi Penelitian Hukum dan jurimetri, Jakarta Ghalia Indonesia.

\section{Peraturan Perundang-undangan :}

Undang-Undang Dasar Negara Republik

Indonesia

Undang-Undang republic Indonesia Nomor 2 Tahun 2002 Tentang kepolisian Negara Republik Indonesia.

Undang-Undang Republik Indonesia Nomor 8 tahun 1981 Tentang Hukum Acara Pidana.

Undang-Undang Nomor 22 Tahun 2009 tentang lalu Lintas dan Angkutan jalan. 